\title{
Contributions of mass spectrometry-based proteomics to defining cellular mechanisms and diagnostic markers for systemic lupus erythematosus
}

\author{
Erik A Korte', Patrick M Gaffney ${ }^{2}$ and David W Powell ${ }^{1,3 *}$
}

\begin{abstract}
Systematic lupus erythematosus (SLE) is a complex disease for which molecular diagnostics are limited and pathogenesis is not clearly understood. Important information is provided in this regard by identification and characterization of more specific molecular and cellular targets in SLE immune cells and target tissue and markers of early-onset and effective response to treatment of SLE complications. In recent years, advances in proteomic technologies and applications have facilitated such discoveries. Here we provide a review of insights into SLE pathogenesis, diagnosis and treatment that have been provided by mass spectrometry-based proteomic approaches.
\end{abstract}

\section{Introduction}

Immune-mediated reactions in systemic lupus erythematosus (SLE) affect many different body systems, including the central nervous system (CNS), blood cells, joints, skin, heart, lungs, and kidneys [1]. Although immunesuppressive treatment is effective, there are undesirable side effects and reduced response to treatment in some cases [1-3]. Thus, an important objective in SLE research is the identification of more specific therapeutic targets by defining novel cellular mechanisms of disease. Another objective is the identification of reliable, non-invasive, and quantifiable markers for detection of the early-onset of specific complications. Such markers would enable treatment to be administered most effectively along with

${ }^{*}$ Correspondence: david.powell@louisville.edu

'Department of Biochemistry and Molecular Biology, University of Louisville School of Medicine, 570 South Preston St, Baxter Research Building I, Room 204E, Louisville, KY 40202, USA

Full list of author information is available at the end of the article assessment of positive response to therapy such that the treatment can be modified or stopped in a timely manner to best manage adverse side effects. These markers also provide important pathogenic insight and tools for testing new or improved therapeutics. In addition to clinical features (rash, arthritis), diagnostic information for SLE is also provided by measurement of immune cell profiles and activity, identification of specific autoantibodies, and identification of changes in protein expression profiles in bodily fluid (urine, blood, cerebral spinal fluid).

Mass spectrometry-based proteomic technologies have played an important role in each area of clinical diagnosis as well as the development of a more comprehensive understanding of the underlying disease process using a myriad of diverse sample types and techniques. One of the preferred mass spectrometry methods in proteomics combines one- or two-dimensional liquid chromatography (LC) peptide separation with electro-spray ionization (ESI) tandem mass spectrometry (MS/MS) [4]. This LC-MS/MS methodology allows for a direct and highly sensitive identification of hundreds of individual proteins from virtually any type of biomedical sample [5]. The decision to use one-dimensional versus two-dimensional LC is based on the complexity of the protein sample. Typically, SDS-PAGE bands or spots ( $<30$ proteins) are analyzed by one-dimensional and much more complex samples, such as affinity-purifications and whole cell, tissue, or bodily fluid extracts are analyzed with twodimensional LC-MS/MS. Another type of mass spectrometry that is employed is matrix-assisted laser desorption/ ionization (MALDI)-time of flight (TOF) [6]. With this approach up to 96 individual protein samples are spotted onto a stationary target for analysis. Although the sensitivity of MALDI-TOF is limited to characterizing the 10 to 15 most abundant proteins in each sample, it has the benefit of being a higher throughput platform for lower complexity, pre-fractionated protein mixtures (after gel separation) because each sample is analyzed in minutes whereas a typical one-dimensional LC run 
requires an hour and two-dimensional LC-MS/MS takes 10 to 12 hours. A third mass spectrometry approach is surface-enhanced laser desorption/ionization (SELDI)TOF, a modification of MALDI-TOF [7]. With SELDITOF, different surface components, such as strong anion exchangers or hydrophobic characteristics, allow binding of proteins with certain characteristics while dissimilar proteins are washed away. This allows analysis of targeted subsets of structurally related proteins and reducing the complexity of the sample improves the overall sensitivity or dynamic range of detection. SELDI-TOF results differ from LC-MS/MS and MALDI-TOF-TOF in that the results are given in mass to charge ratios $(\mathrm{m} / \mathrm{z})$ rather than peptide sequence, so positive protein identification is not possible. It is, however, useful for rapid analysis of the protein $\mathrm{m} / \mathrm{z}$ profiles of semi-complex samples by reducing upfront separation while preserving the fast analysis time of a MALDI platform. Although not as desirable for discovery, these attributes of relative ease of sample preparation and speed of analysis and data output, as well as lower startup and operation costs, present SELDI-TOF as a more suitable mass spectrometry platform for a clinical test.

A key component of these studies is the method used to prepare selectively targeted protein samples for mass spectrometry interpretation. Auto-antigen identification studies usually involve separation of the tissue of interest by one-dimensional or two-dimensional electrophoresis SDS-PAGE, followed by immuno-blotting with anti-sera from SLE patients, and identification of proteins in immune-reactive bands by MALDI-TOF-TOF or LCMS/MS analysis [8]. Another approach isolates autoantibodies from SLE patient serum using immobilized protein G, which is then used to affinity enrich antigens in targeted tissue extracts for direct characterization with two-dimensional LC-MS/MS analysis [9]. Studies aimed at defining diagnostic markers for SLE complications by comparing protein expression in normal and diseased bodily fluids have used two basic approaches: assessment of protein expression differences from stained twodimensional gels followed by MALDI-TOF-TOF identification of the proteins in differing spots; or direct assessment and comparison of protein expression from intrinsic LC-MS/MS data $[8,10]$. The work flow of these applications is described in Figure 1.

In this review we seek to explain prior contributions of mass spectrometry techniques to the biological understanding, diagnosis and treatment of SLE and to lay out a framework for future work in the field. It is our hope that the subsequent information will allow a greater understanding of the mass spectrometry-based techniques and illustrate their potential in translational and clinical research related to SLE and other autoimmune diseases.

\section{Cardiovascular systemic lupus erythematosus}

A great deal of effort has been put into understanding the changes to the cardiovascular system in SLE. Cardiac involvement in SLE has been reported with a prevalence up to $50 \%$ [11], but on average only $9 \%$ will develop true myocarditis $[12,13]$. SLE has long been known to result in immune deposits in the pericardium and/or myocardium of SLE patients, resulting in both histopathologic and gross anatomic changes [14]. Arrhythmias, including sinus tachycardia, atrial fibrillation, long QT, atrioventricular block and bundle branch block, are rare complications, but can have significant effects when combined with other factors such as antimalarial therapy [13] and studies have reported up to $16 \%$ of children with SLE to have asymptomatic cardiovascular disease [15]. The risk of developing coronary artery disease is four to eight times higher in SLE patients than in controls, and this risk increases to 50-fold in young women [16]. Treatment can be tailored to specific patients at risk for the development of such complications, but for this to be possible, early diagnosis of SLE is required followed by the accurate gauging of cardiovascular risk. Mass spectrometry findings have been used to characterize the proteomic changes in the SLE disease state to better understand the pathogenic mechanisms behind cardiovascular disease to allow earlier diagnosis and improved risk assessment [10,17-20].

To better understand pathogenesis of cardiovascular SLE and provide biomarkers for prompt diagnosis, autoantigens involved in congenital heart block were subjected to proteolytic cleavage with and without sera of SLE patients, followed by MALDI-TOF-TOF identification of antibody-protected sites (epitopes) [19]. The resulting peptides were found to correspond to the 200 to 239 amino acid portion of the Ro52 protein, supporting the use of autoantibodies against Ro52 as a biomarker. Subsequent studies have supported the role of anti-Ro antibodies (both Ro52 and Ro60) in congenital heart block and suggested potential mechanisms for the development of the condition [21,22].

Haptoglobin $\alpha 2$ polypeptide chain differences have been noted between SLE and non-SLE populations via MALDI-TOF mass spectrometry [23]. Patients expressing the haptoglobin $\alpha 2$ isoform have been shown to have shorter survival times after coronary artery bypass graft [24] and more severe complications after myocardial infarction [25], possibly due to decreased ability to reduce oxidative stress. The association of haptoglobin $\alpha 2$ peptides with SLE flare may offer insight into the cardiac complications seen in SLE and higher levels of haptoglobin $\alpha 2$ have been reported in SLE patients versus controls [23].

To identify target autoantigens and explore the pathogenesis of dilated cardiomyopathy, Seko and colleagues 


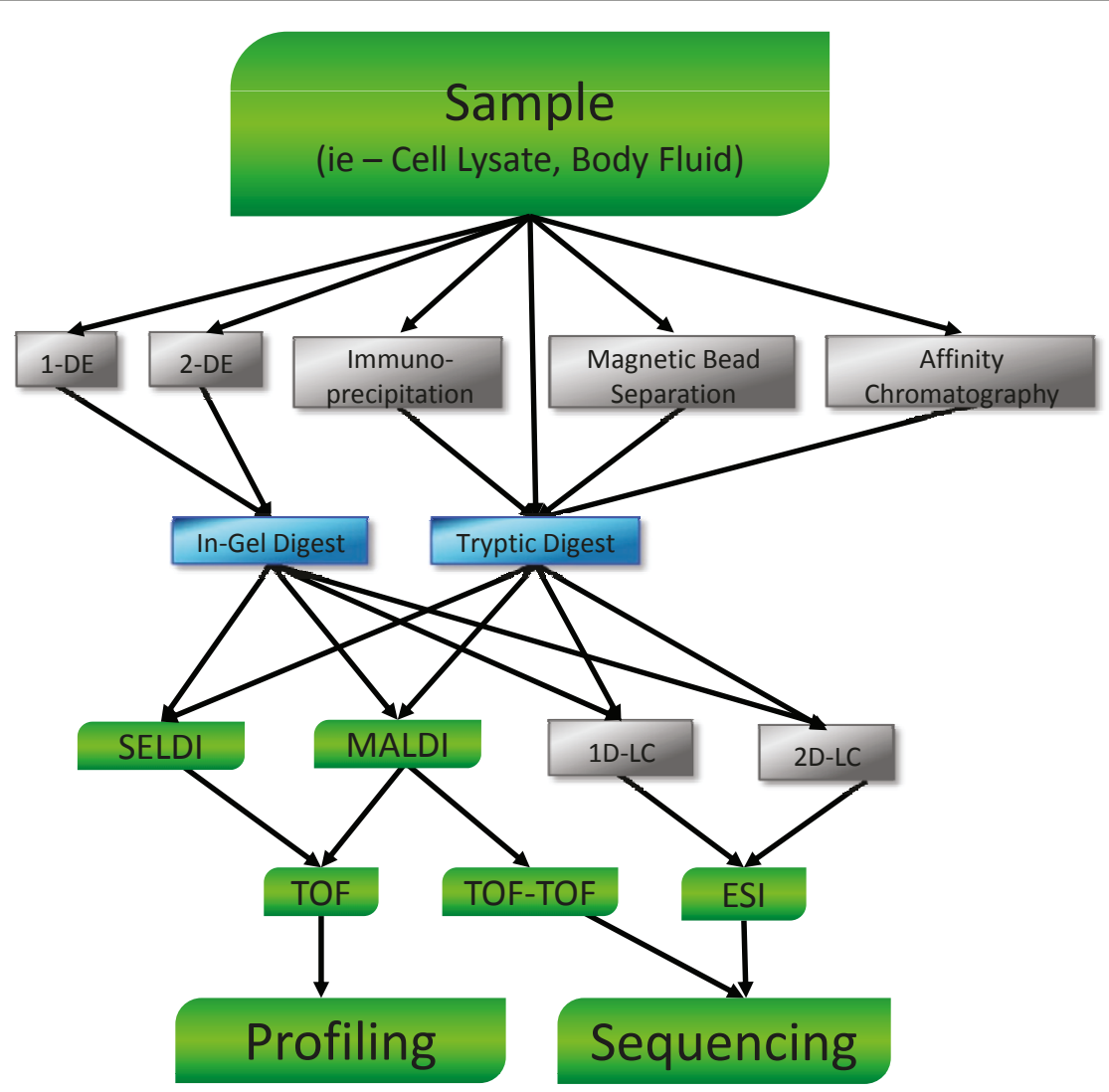

Figure 1. Mass spectrometry workflow. Starting from sample, which could be any preparation of proteins, a work flow could lead to a number of separation/purification techniques or proceed directly to tryptic digestion. Both one- and two-dimensional electrophoresis (1-DE and 2-DE) are used to immunoblot for novel autoantigens followed by analysis, frequently matrix-assisted laser desorption/ionization (MALDI) or surfaceenhanced laser desorption/ionization (SELDI), but also including one-dimensional and two-dimensional liquid chromatography (1D-LC and 2D-LC)-tandem mass spectrometry (MS/MS). Complex samples may be separated by affinity chromatography, immunoprecipitation or magnetic bead separation. Techniques may be employed to remove primarily high-abundance proteins, separated based on protein chemistry or interaction kinetics involving immunoglobulins or other proteins. The digested peptides could be subjected to analysis by MALDI, SELDI, and one- or twodimensional electrospray ionization (ESI)-LC/MS/MS. Gel separated and digested proteins are frequently analyzed with MALDI or SELDI platforms, but are appropriate for ESI as well. More complex sample types, in particular whole cell lysates, which have not been separated, are frequently subjected to one- or two-dimensional LC peptide separation coupled with ESI-MS/MS analysis. The two-dimensional aspect of LC separation allows a greater number of proteins to be identified from very complex samples when compared to the other methods, with the tradeoff being the greatly increased time (10 to 12 hours) to analyze one sample. SELDI-time-of-flight (TOF) and MALDI-TOF are used for profiling while MALDI-TOFTOF and ESI-MS/MS can sequence the peptides in the sample to positively identify their parent proteins.

[10] applied a two-dimensional electrophoresis separation approach to plasma membrane proteins isolated from rat cardiac myocyte cultures. The protein blot was then probed with serum of healthy controls as well as a 17-year-old patient with an unusual presentation of delayed cardiomyopathy subsequent to neonatal lupus erythematosus. While the control showed no significant reactivity, many immune-reactive spots appeared on the sample probed with SLE serum, which were excised and analyzed on a LC-MS/MS system. The analysis identified two high-probability proteins: annexin A6, known for calcium signaling and membrane trafficking, and vimentin, known for maintenance of cellular structure (Table 1). The authors downplayed the likelihood of vimentin playing a role in the pathogenesis of myocardial contractile dysfunction. However, mice with overexpressed annexin A6 had decreased contraction and relaxation of cardiac myocytes as well as dilated cardiomyopathy [26], suggesting that if autoantibodies to annexin A6 stimulate its function, then the result would be suppression of myocardial activity.

\section{Immune cell involvement in systemic lupus erythematosus}

SLE is, at its core, a disease of the immune system, so a deeper understanding of immune cell function in both normal and diseased states is critical for a comprehensive understanding of SLE. Complementary studies by Dai 
Table 1

\begin{tabular}{|c|c|c|c|}
\hline Protein identified & MS platform & Authors' conclusion & $\begin{array}{l}\text { Biomarker or } \\
\text { mechanistic }\end{array}$ \\
\hline \multicolumn{4}{|l|}{ Cardiovascular SLE } \\
\hline Haptoglobin (Hp)a2 [23] & $\begin{array}{l}\text { MALDI-TOF-TOF } \\
\text { and ESI-MS/MS }\end{array}$ & $\begin{array}{l}\text { Higher plasma Hpa2 seen in SLE versus controls } \\
\text { Supporting research has implicated Hpa2 isoforms in cardiac } \\
\text { complications }[24,25]\end{array}$ & Both \\
\hline Ro52 [19] & MALDI-TOF-TOF & $\begin{array}{l}\text { Antibody protected sites found with SLE sera in portion of the Ro52 protein } \\
\text { comprising amino acids } 200 \text { to } 239\end{array}$ & Both \\
\hline Annexin A6 [10] & LC-MS/MS & $\begin{array}{l}\text { Autoantibodies identified against annexin A6 } \\
\text { Activation of annexin A6 via autoantibody resulting in impaired heart function }\end{array}$ & Both \\
\hline \multicolumn{4}{|l|}{ Immune cell involvement in SLE } \\
\hline Immunoglobulin J [27] & MALDI-TOF & $\begin{array}{l}\text { Upregulated in SLE } 2.46 \text {-fold } \\
\text { Early differentiation marker for B cells }\end{array}$ & Both \\
\hline Calprotectin L1 [27] & MALDI-TOF & $\begin{array}{l}\text { Upregulated in SLE 2.02-fold } \\
\text { Known marker of disease activity in RA } \\
\text { Released from granulocytes and monocytes during their activation } \\
\text { Significantly tied to SLEDAl and higher levels of anti-double-stranded DNA } \\
\text { antibodies and SLE arthritis } \\
\text { May also inhibit immunoglobulin production }\end{array}$ & Both \\
\hline $\begin{array}{l}\text { Glutathione S-transferase } \\
{[18,27]}\end{array}$ & $\begin{array}{l}\text { MALDI-TOF and } \\
\text { iTRAQ 2D LC-MS/MS }\end{array}$ & $\begin{array}{l}\text { Downregulated in SLE } 0.15 \text {-fold }(P=0.001) \text { in one study and versus diseased } \\
\text { and healthy controls } \\
\text { Lower GST results in higher ROS levels and increased oxidative stress } \\
\text { Polymorphisms with altered enzyme activity of GST have been shown to } \\
\text { lead to SLE }\end{array}$ & Both \\
\hline $\begin{array}{l}\text { Apolipoprotein A-IV } \\
\text { precursor [27] }\end{array}$ & MALDI-TOF & $\begin{array}{l}\text { Upregulated in SLE 2.67-fold }(P=0.010) \\
\text { Similar results seen in RA [70] and Alzheimer's disease [71] }\end{array}$ & Biomarker \\
\hline $\begin{array}{l}\text { Zinc finger protein } \\
\text { subfamily } 1 \mathrm{~A}[27]\end{array}$ & MALDI-TOF & Upregulated in SLE 2.24-fold ( $P=0.041)$ & Both \\
\hline $\begin{array}{l}\text { Zinc finger protein - } \\
\text { isoform } 2 \text { protein } 549 \text { [18] }\end{array}$ & iTRAQ 2D LC-MS/MS & $\begin{array}{l}\text { Upregulated in active SLE versus stable SLE (2.7160), RA (2.3824) and healthy } \\
\text { controls (3.1042) }\end{array}$ & Both \\
\hline Resistin [18] & iTRAQ 2D LC-MS/MS & $\begin{array}{l}\text { Upregulated in active SLE versus stable SLE (3.6784) and healthy controls (2.2652) } \\
\text { Verifies previous findings }\end{array}$ & Both \\
\hline S100-P [18] & iTRAQ 2D LC-MS/MS & Upregulated in active SLE versus stable SLE (2.9641), and healthy controls (2.6475) & Both \\
\hline S100-A12 [18] & iTRAQ 2D LC-MS/MS & Upregulated in active SLE versus stable SLE (2.3374), RA (2.0595) & Both \\
\hline $\begin{array}{l}\text { Brain acid soluble } \\
\text { protein } 1[18]\end{array}$ & iTRAQ 2D LC-MS/MS & Upregulated in active SLE versus stable SLE (2.1139), healthy controls (2.6622) & Both \\
\hline $\begin{array}{l}\text { Ras-related C3 botulism } \\
\text { toxin substrate } 2[18]\end{array}$ & iTRAQ 2D LC-MS/MS & Downregulated in stable SLE (0.4663) versus diseased controls & Both \\
\hline \multicolumn{4}{|l|}{ Lupus nephritis } \\
\hline a-1 Acid glycoprotein [34] & 2-DE then MALDI-TOF & Diagnosis and class identification of LN & Biomarker \\
\hline a1 Microglobulin [34] & 2-DE then MALDI-TOF & Diagnosis and class identification of $L N$ & Biomarker \\
\hline Zinc a-2 glycoprotein [34] & 2-DE then MALDI-TOF & Diagnosis and class identification of $L N$ & Biomarker \\
\hline IgG k light chain [34] & 2-DE then MALDI-TOF & Diagnosis and class identification of LN & Biomarker \\
\hline a-1 Antitrypsin [36] & $\begin{array}{l}\text { SELDI-TOF then } \\
\text { LC-MS/MS }\end{array}$ & $\begin{array}{l}\text { Upregulated in the urine at baseline and } 2 \text { months pre-flare until } 4 \text { months } \\
\text { post-flare }\end{array}$ & Biomarker \\
\hline Albumin [36] & $\begin{array}{l}\text { SELDI-TOF then } \\
\text { LC-MS/MS }\end{array}$ & Upregulated in the urine at baseline versus flare & Biomarker \\
\hline Hepcidin-20 [36,37] & $\begin{array}{l}\text { SELDI-TOF then } \\
\text { LC-MS/MS }\end{array}$ & Upregulated in the urine 4 months pre-flare & Biomarker \\
\hline Aldolase A [20] & LC-MS/MS & $\begin{array}{l}\text { Autoantibodies more common in LN patients than SLE without LN } \\
\text { Antibody specific to a } 94 \text { to } 183 \text { amino acid epitope may be } \\
\text { LN-specific biomarker }\end{array}$ & Biomarker \\
\hline
\end{tabular}


Table 1 (continued)

\begin{tabular}{|c|c|c|c|}
\hline Protein identified & MS platform & Authors' conclusion & $\begin{array}{l}\text { Biomarker or } \\
\text { mechanistic }\end{array}$ \\
\hline \multicolumn{4}{|l|}{ Pediatric lupus nephritis } \\
\hline Transferrin (Tf) $[38,39]$ & $\begin{array}{l}\text { SELDI-TOF then } \\
\text { MALDI-TOF MS/MS }\end{array}$ & $\begin{array}{l}\text { Upregulated in worsening disease and flares in pediatric patients } \\
\text { Plasma Tf related to global SLE activity } \\
\text { Urine Tf was related to LN disease activity }\end{array}$ & Biomarker \\
\hline Ceruloplasmin (Cp) [38,39] & $\begin{array}{l}\text { SELDI-TOF then } \\
\text { MALDI-TOF MS/MS }\end{array}$ & $\begin{array}{l}\text { Upregulated in pediatric SLE and LN, but cannot specify between different } \\
\text { classes of LN activity }\end{array}$ & Biomarker \\
\hline $\begin{array}{l}\text { a1-Acid-glycoprotein } \\
\text { (AGP) [38,39] }\end{array}$ & $\begin{array}{l}\text { SELDI-TOF then } \\
\text { MALDI-TOF MS/MS }\end{array}$ & $\begin{array}{l}\text { AGP from plasma is for global pediatric SLE } \\
\text { AGP from urine is specific to pediatric LN } \\
\text { Useful to anticipate renal flares }\end{array}$ & Biomarker \\
\hline Lipocalin $[38,39]$ & $\begin{array}{l}\text { SELDI-TOF then } \\
\text { MALDI-TOF MS/MS }\end{array}$ & $\begin{array}{l}\text { Type prostaglandin-D synthetase (L-PGDS) - role in chemotherapy induced } \\
\text { renal damage (plasma and urine) } \\
\text { Novel to LN }\end{array}$ & Biomarker \\
\hline Aldolase A [20] & LC-MS/MS & $\begin{array}{l}\text { Anti-aldolase A antibodies have been found to be more common in SLE with } \\
\text { LN than SLE without LN ( } 43.4 \% \text { to } 11.1 \%) \\
\text { Possible specificity for other autoimmune conditions via presence of antibodies } \\
\text { to the } 94 \text { to } 183 \text { amino acid epitope }\end{array}$ & Biomarker \\
\hline \multicolumn{4}{|l|}{ Neurophychiatric SLE } \\
\hline $\begin{array}{l}\text { Intermediate filament } \\
\text { a-internexin (INA) [8] }\end{array}$ & $\begin{array}{l}\text { 2-DE then } \\
\text { MALDI-TOF }\end{array}$ & $\begin{array}{l}\text { Reactive antibodies found in NPSLE patient sera in } 41.7 \% \text { of patients } \\
\text { ( } 7.1 \% \text { of SLE, } 0 \% \text { healthy controls and } 10 \% \text { of other neurological diseases) } \\
\text { Results verified [45] }\end{array}$ & Both \\
\hline a-Tubulin [43] & $\begin{array}{l}\text { MALDI-TOF then } \\
\text { Q-TOF }\end{array}$ & $\begin{array}{l}\text { Autoantibodies were found in 36\% of NPSLE (versus } 4 \% \text { of SLE and 0\% } \\
\text { healthy controls) } \\
\text { More frequently seen in severe (50\%) than mild (20\%) NPSLE } \\
\text { Confirmed by LC-MS/MS [9] }\end{array}$ & Both \\
\hline$\beta$-Tubulin [43] & $\begin{array}{l}\text { MALDI-TOF then } \\
\text { Q-TOF }\end{array}$ & $\begin{array}{l}\text { Previously identified in other autoimmune conditions such as multiple } \\
\text { sclerosis and Guillain-Barre syndrome } \\
\text { Confirmed by LC-MS/MS [9] }\end{array}$ & Both \\
\hline Crystalline aB [9] & LC-MS/MS & Novel sera and CSF autoantigen for active NPSLE & Both \\
\hline Esterase D [9] & LC-MS/MS & Novel sera and CSF autoantigen for active NPSLE & Both \\
\hline APEX nuclease 1 [9] & LC-MS/MS & $\begin{array}{l}\text { Novel sera and CSF autoantigen for active NPSLE } \\
\text { More reactive in SLE than other autoimmune conditions }\end{array}$ & Both \\
\hline $\begin{array}{l}60 \mathrm{kDa} \text { Heat shock } \\
\text { protein [45] }\end{array}$ & LC-MS/MS & $\begin{array}{l}\text { Autoantibodies directed against cerebral lysates found in sera of NPSLE patients } \\
\text { with WMH } \\
\text { Known to cause endothelial cell apoptosis and coronary artery disease } \\
\text { Results verified [32] }\end{array}$ & Both \\
\hline $\begin{array}{l}\text { Anti-Rab guanosine } \\
\text { diphosphate dissociation } \\
\text { inhibitor a [31] }\end{array}$ & LC-MS/MS & $\begin{array}{l}\text { Found in } 80 \% \text { of NPSLE patient sera with psychosis (versus 5.3\% of NPSLE } \\
\text { without psychosis and none of the CNS control samples) }\end{array}$ & Both \\
\hline
\end{tabular}

1D, one-dimensional; 2D, two-dimensional; 2-DE, two-dimensional electrophoresis; AGP, a1-acid-glycoprotein; CNS, central nervous system; CSF, cerebral spinal fluid; ESI, electrospray ionization; GST, glutathione S-transferase; iTRAQ, isobaric tagging for relative and absolute protein quantification; LC, liquid chromatography; LN, lupus nephritis; L-PGDS, lipocalin-type prostaglandin-D synthetase; MALDI-TOF, matrix associated laser desorption/ionization-time of flight; MS/MS, tandem mass spectrometry; NPSLE, neuropsychiatric systemic lupus erythematosus; RA, rheumatoid arthritis; ROS, reactive oxygen species; SELDI, surface enhanced laser desorption/ionization; SLE, systemic lupus erythematosus; SLEDAI, SLE Disease Activity Index; Tf, tranferrin; WMH, white matter hypertrophies (on MRI).

and colleagues [27] and Wang and colleagues [18] show the evolution of a mass spectrometry-based interpretation of peripheral blood mononuclear cells (PBMCs) in SLE. Dai and colleagues published their work in 2008 comparing the relative changes in the proteome of PBMCs of both healthy controls and SLE patients. They employed the conventional approach of two-dimensional electrophoresis and silver stain followed by MALDITOF-TOF to identify protein spots expressed at different levels. A total of 20 spots differed significantly between the SLE and control group, with 11 being upregulated and 9 downregulated. The findings of the study are summarized in Table 1. Briefly, immunoglobulin J chain, an early differentiation marker in B cells, was upregulated, as was calprotectin L1, a protein released by granulocytes and monocytes during activation. Interestingly, calprotectin L1 levels were associated with the severity of disease and at the same time were linked significantly to anti-double-stranded DNA antibodies. Glutathione S-transferase (GST) was downregulated in SLE, which would 
reduce the cell's ability to degrade reactive oxygen species, which may contribute to inflammation and tissue damage.

Wang and colleagues [18] followed Dai two years later with an expanded study that employed the use of isobaric tagging for relative and absolute protein quantification (iTRAQ) as a means of studying PBMC proteome changes. The iTRAQ method was used with LC-MS/MS to allow multiplexing of samples (up to eight per run), which not only saves time but also reduces technical variability. Using six samples each for active SLE, inactive SLE, rheumatoid arthritis (RA) as a diseased control and healthy patient samples, 452 proteins with a variety of cellular locations and biological functions were identified and quantified. Of these, 126 were either upregulated or downregulated across all the groups. When compared to the 2008 data, this study showed a similar downregulation of glutathione S-transferase and upregulation of zinc finger proteins with similar fold changes in both experiments, but also identified several other known SLE regulators and novel functional candidates. In total, 17 proteins were upregulated and 13 were downregulated in active versus stable SLE. The authors' choices for future study are listed in Table 1. Known SLE and inflammatory proteins were identified, such as resistin and calciumbinding family of S100 proteins. Additionally, several novel candidate proteins were identified, such as brain acid soluble protein 1 and ras-related C3 botulism toxin substrate 2, which have roles in apoptotic mechanisms in other diseases $[28,29]$, but this was their first link to SLE disease activity.

\section{Lupus nephritis}

Lupus nephritis (LN) must be considered in a discussion on the use of proteomic methods in lupus, because $\mathrm{LN}$ is one of the most common and most severe complications that can arise from SLE (affecting approximately 50\% of patients), leading to significant morbidity and mortality [30]. As with other renal disorders, a major diagnostic source for $\mathrm{LN}$ is urine. The advantage of using urine as a screening method for the presence or severity of disease is the non-invasive nature of sample collection. Urine studies also allow long-term observation of patients, allowing tracking of changes in the urine proteome associated with changing disease states. SLE and LN biomarkers have been a topic of discussion dating back to the 1960s and continue to be of interest today [20,31-33]. Recent proteomic studies have provided insight into novel urinary biomarkers for $\mathrm{LN}$.

Oates and colleagues [34] built on the ideas of urine protein quantification using two-dimensional electrophoresis to train an artificial neural network capable of identifying potentially significant changes to urine proteomes immediately before validation by renal biopsy.
Briefly, $200 \mu \mathrm{g}$ of protein were collected from 20 different patients with SLE at the time of biopsy. The recovered protein was denatured and separated using two-dimensional electrophoresis. A total of 213 protein spots across the 20 patient gels were used to calculate protein abundance and an artificial neural network was trained to identify the class of $\mathrm{LN}$ based on the protein abundance profile. The resulting neural network was able to successfully identify $>86 \%$ of all positives and $>92 \%$ of all negatives, with the exception of class $V$, where each false positive was present in a sample also positive for class III or IV LN, which were correctly identified. The group then identified the most critical spots for determining sensitivity and subjected each to MALDI-TOF mass spectrometry, which identified six proteins: $\alpha-1$ acid glycoprotein, $\alpha_{1}$ microglobulin (two spots), zinc $\alpha-2$ glycoprotein (two spots), and IgG $\kappa$ light chain (Table 1).

Early work successfully identified proteomic profiles of renal flare in SLE through the use of SELDI-TOF to identify protein signatures without the need to positively identify proteins. This allowed the identification of novel biomarkers, but the protein identification limitation of the SELDI-TOF technique prevented mechanistic inference and predictions [35]. Zhang and colleagues [36] provided both diagnostic and mechanistic understanding of LN using longitudinal urine proteomics to assess the changes in the urine proteome before, during and after SLE renal flare by combining SELDI-TOF with LC-MS/ MS sequencing for protein identification. Using a sample set of 145 urine specimens from SLE class III, IV and V patients, they identified 27 low molecular weight proteins that showed significantly different levels of expression before, during or after SLE flare. While no single peptide was present in all the flare or non-flare samples, combinations of two peptides were found that successfully differentiated $100 \%$ of the remission and pre-flare samples from flare and post-flare samples. LC-MS/MS analysis identified multiple isoforms of $\alpha-1$ antitrypsin, albumin, and hepcidin as proteins of interest (Table 1). Interestingly, hepcidin-20 levels were only altered preflare, which means it may be a useful indicator of impending flare, allowing modulation of clinical management to reduce severity and duration of the flare. A follow up study two years later supported this idea and further presented interleukin-6- and interferon- $\alpha$-dependent upregulation of hepcidin transcription as a possible mechanism of hepcidin increase in LN [37].

A study using LC-MS/MS to characterize immunereactive bands from two-dimensional electrophoresis separated endothelial cell lysate with sera of SLE patients, other autoimmune conditions and healthy controls identified the glycolytic enzyme aldolase $\mathrm{A}$ as a candidate target antigen [20] (Table 1). Moreover, this was found to be more common for LN patients than in SLE without 
LN (43.4\% with LN versus $11.1 \%$ without LN). However, reactivity to aldolase A was not appropriately significant between LN and other inflammatory disease controls such as RA and polymyositis to be used as a stand-alone biomarker for LN. The authors did, however, note specificity of LN patient anti-sera to the region of aldolase A comprising amino acids 94 to 183 over other autoimmune conditions.

Suzuki and colleagues used a combination of SELDITOF [38] and MALDI-TOF [39] for evaluation of the urine proteome in pediatric LN. Four potentially significant biomarkers were identified, including transferrin (Tf), ceruloplasmin, $\alpha 1$-acid-glycoprotein (AGP), and lipocalin-type prostaglandin-D synthetase (L-PGDS), each with great significance $(P<0.005$; Table 1$)$. Significant increases of Tf, L-PGDS, and AGP were seen as early as three months before clinical diagnosis or worsening of LN. Both Tf and AGP were also seen in adult forms of the disease [40], while L-PGDS is novel to pediatric LN diagnosis. Ceruloplasmin has been implicated in global SLE, but was not found to be an effective metric for defining the course of $\mathrm{LN}$ in pediatric patients.

\section{Neuropsychiatric systemic lupus erythematosus}

Neuropsychiatric SLE (NPSLE) is a potentially severe complication that varies in prevalence between $9.5 \%$ and 95\% based on the literature and the diagnostic criteria [41]. Findings suggest that NPSLE can be present in a mild form in as many as $95 \%$ of SLE patients [42], making it more common but typically less severe than renal or cardiovascular complications. Mood disorders and cognitive disorders are common symptoms and can be particularly challenging to diagnose in pediatric and adolescent patients due to the rapid emotional and physical changes that occur at those ages. While acquisition of cerebral spinal fluid (CSF) is invasive, it has become routine in the diagnosis of many neurological diseases and, in addition to serum, is therefore a useful medium for proteomic study of NPSLE. NPSLE research has focused on both biomarker identification for its diagnostic value as well as autoantigen identification for improved mechanistic understanding of the disease state and potential therapeutic development.

$\mathrm{Lu}$ and colleagues [8] found CSF and sera obtained from NPSLE patients to be reactive to rat, mouse and monkey brain homogenate when separated by twodimensional electrophoresis. MALDI-TOF-TOF was used to identify immune-reactive proteins. A total of 275 serum samples and 177 CSF samples were included, giving a great deal of depth and statistical power to the study. Briefly, four antinuclear antibody (ANA)-positive serum samples, which did not react to Hep2 cells, were used as pilot samples. Initial analysis of the reactive spots revealed an interaction in three of four samples with $\alpha$-internexin (INA), a highly conserved protein between rodents and humans (Table 1). Recombinant human INA was then used in a western blot to confirm reactivity of sera as well as immunofluorescence with sera and antiINA polyclonal antibody. Both the sera and the polyclonal antibody were found to react to cultured rat cortical neurons and the reactivity of sera was reduced by incubation with recombinant INA. These findings opened the door for analysis of the entire cohort of CSF and serum samples. Using two standard deviations as a cutoff for positivity, $41.7 \%$ of the NPSLE samples of CSF were found to be positive for anti-INA antibodies (compared to $0 \%$ of SLE with cerebral infarction, $7.1 \%$ of normal SLE controls, and $10 \%$ of other neurological diseases). In total, the data showed reactivity in more than $40 \%$ of NPSLE patients in a dose-dependent manner toward INA. Longitudinal studies found that antibody levels were inversely proportional to cognitive level and declined after initiation of therapy and clinical remission. Furthermore, mice immunized with INA plus lipopolysaccharide developed cognitive impairments similar to NPSLE and exhibited hippocampal and cortical neuron apoptosis, suggesting that the presence of antiINA antibodies in the serum of patients was pathogenic.

Ndhlovu and colleagues [43] identified $\alpha$ - and $\beta$-tubulin as target autoantigens for NPSLE using patient sera to probe isolated mitochondria from bovine brain followed by MALDI-TOF analysis. Autoantibodies to $\beta$-tubulin have been identified in other CNS targeting autoimmune diseases such as Guillain-Barre syndrome, multiple sclerosis, and Sydenham's chorea, but targeting of $\alpha$ tubulin is potentially specific to NPSLE. $\alpha$-Tubulin autoantibodies were present in 36\% of NPSLE patient sera, only $4 \%$ of SLE patients without neurological symptoms and none of the multiple sclerosis, epileptic or healthy control samples (Table 1). Possibly due to the small size of the NPSLE population in the study $(n=37)$, no correlation was seen between specific symptoms of NPSLE and the presence of $\alpha$-tubulin autoantibodies in sera. Larger patient population studies are needed to further explore the involvement of anti- $\alpha$-tubulin antibodies in NPSLE.

LC-MS/MS incorporates a direct front-end separation of complex samples to greatly increase the sensitivity of the procedure for low abundance protein detection. LCMS/MS may be superior to MALDI-based techniques when dealing with complex samples. Katsumata and colleagues found this to be true while attempting to uncover novel serum autoantibodies for SLE, in particular those involved in CNS syndromes [9]. Whole protein extracts from human neuroblastoma and glioblastoma cell lines were separated using two-dimensional electrophoresis and reacted to patient sera. It was determined that MALDI-TOF sensitivity was too low for 
effective protein identification in this case. To address this concern, anti-sera from SLE patients with and without CNS syndromes was bound to protein Gsepharose beads and incubated with the same cell line extracts. Proteins pulled down with the sepharose beads were analyzed with a LC-MS/MS method using a Q-TOF instrument. Most of the 154 proteins identified by the LC-MS/MS approach were not identified in the twodimensional electrophoresis/MALDI-TOF analysis and 50 were found in the CNS group but not the non-CNS group. After exclusion of previously described autoantigens, 11 recombinant candidates showed reactivity against pooled serum of 28 patients with active CNS SLE by western blot analysis ( 5 of which were only detected by LC-MS/MS). These 11 candidates were then probed with sera of 106 SLE patients (42 with active CNS syndromes) as well as 100 healthy controls, resulting in a list of 5 confirmed autoantigens, 3 of which were novel (crystalline $\alpha \mathrm{B}$, esterase D and APEX nuclease 1; Table 1). When compared to other diseased sera (RA, systemic sclerosis, Sjögren's syndrome, and multiple sclerosis), levels of anti-crystalline $\alpha B$ were not found to be significantly different. Anti-APEX nuclease 1 and esterase $\mathrm{D}$, on the other hand, had significantly higher levels in SLE than in these disease controls and between CNS and non-CNS SLE sera. APEX nuclease 1 is the major apurinic/apyrimidinic endonuclease in human cells and is found to be upregulated in tissues under oxidative stress and has a significant effect on apoptotic regulation in certain tissues [44]. The effects of esterase D are less well known.

In a similar study, Kimura and colleagues [45] used a combination two-dimensional electrophoresis and LCMS/MS with an ESI-LCQ instrument to obtain higher sensitivity for low abundance proteins. Patient sera from a NPSLE patient with white matter hyperintensities on T2-weighted MRI scan was reacted to a two-dimensional electrophoresis rat cerebral lysate blot. In total, nine reactive spots were seen and five were analyzed by LCMS/MS. The two spots of greatest intensity corresponded to $60 \mathrm{kDa}$ heat shock protein (Hsp60) [45], which functions to refold proteins that are misfolded and/or facilitate degradation of proteins that cannot be recovered [46]. Enhanced expression of Hsp60 can induce endothelial cell apoptosis and Hsp60 expression on the surface of endothelial cells has been reported to be directly related to coronary artery disease [47], opening the possibility of a similar relationship in the cerebral vasculature. In a follow-up study of 180 patients with neurological diseases (including 15 with SLE) and 23 healthy controls, Kimura and colleagues showed that the titer levels of anti-Hsp60 antibodies were directly correlated to severity of white matter hyperintensities in the brain, suggesting the presence of anti-Hsp60 antibodies as both a diagnostic tool as well as a mechanistic agent in the development of NPSLE [32]. Although the authors chose to focus on Hsp60, the study also found SLE-specific antibodies to $\alpha$-internexin, $\beta$-actin, and glial fibrillary acidic protein (Table 1 ).

Another study using LC-MS/MS also suggested a relationship between NPSLE exhibiting psychosis with anti-Rab GDP dissociation inhibitor alpha ( $\alpha$ GDI) [31]. LC-MS/MS and western blot analysis of sera found that 4 of 5 patients with NPSLE with psychosis (80\%) expressed anti-Rab $\alpha$ GDI (Table 1), while 1 of 13 patients with NPSLE and none with psychosis (5.3\%) expressed the autoantibody, along with no expression in patients with multiple sclerosis $(n=12)$, infectious meningoencephalitis $(\mathrm{n}=13)$, polyneuropathy $(\mathrm{n}=10)$, psychotic syndromes $(n=10)$, or healthy controls $(n=12)$.

\section{Other uses for proteomics in the study of SLE}

Aside from assessing differences in disease states, pharmacologic reactions can be measured using proteomic techniques. Kao and colleagues [48] used two-dimensional electrophoresis and MALDI-TOF to investigate the changes to apoptotic-prone macrophages (APMs) from lupus-prone NZB/W-F1 mice before and after treatment with cystamine, a known inhibitor of transglutaminase 2 activities. A number of the findings indicated that cystamine has an anti-apoptotic affect in APMs and suggests a possible mechanism of this activity. The protein expression and enzyme activity of caspase 3 were downregulated and anti-apoptotic proteins APIP, PEBP4, and $\mathrm{Bcl}-2$ were upregulated. ERK1/2 showed reduced phosphorylation after treatment in APMs, which also would result in survival of APMs and fewer apoptotic bodies to serve as potential targets for autoantibody production. Previous studies have shown that ERK1/2 phosphorylation is increased with cystamine treatment in endothelial cells [49] and neuronal tissue [50]; therefore, the findings of decreased phosphorylation in APMs may help further explain the development of SLE in specific tissues and lead to a more complete model of pathogenesis.

Mass spectrometry can also be useful as a supplemental technique of a study. In work primarily focused on genetics, D'souza and colleagues [51] utilized MALDITOF mass spectrometry to support the hypothesis that catalase polymorphisms affect the risk and severity of SLE. Oxidative processes resulted in the 4-hydroxy 2-nonenol adducts on membrane catalase of red blood cells. MALDI-TOF was of great use in this situation because it allowed the positive identification of catalase from red blood cell membranes (an uncommon location) while migrating at a higher molecular weight, possibly due to 4-hydroxy 2-nonenol adducts. Ye and colleagues [52] expanded on previous microarray data by selecting a 
gene that is upregulated in SLE, IFIT1 (interferoninduced with tetratricopeptide repeats 1), creating a IFIT1 fusion protein with GST, and then using bead immobilized GST-IFIT1 as bait to capture interacting proteins in white blood cell lysate. MALDI-TOF was performed on the proteins pulled down in the procedure and found Rho/Rac guanine nucleotide exchange factor to be a potential target for IFIT1 interaction in SLE. Follow-up studies have supported the role of the interferon pathway in SLE and other autoimmune diseases [53-55].

\section{Conclusion}

Many of the studies presented in this review were aimed at using proteomic applications to define events in specific SLE complications, but it is our view some of these discoveries could also provide insight into other areas of SLE or that approaches applied to similar diseases could be modified for use in SLE. Recent studies have shown the use of MALDI-TOF techniques for synovial fluid analysis in autoimmune arthritis [56], which could be used to assess changes in SLE arthritis. Kimura and colleagues [45] identified a $60 \mathrm{kDa}$ heat shock protein as an autoantigen in NPSLE, a protein with known ties to coronary artery disease and endothelial cell apoptosis $[47,57,58]$, that may play a role in the development of cardiovascular SLE. Several studies have shown the benefits of proteomics using bronchoalveolar lavage fluid as a sample for the study of sarcoidosis [59], systemic sclerosis $[60,61]$, and other pulmonary diseases $[62,63]$. The use of bronchoalveolar lavage fluid for the study and diagnosis of pulmonary complications in SLE would be less invasive and safer than biopsy. Tamburro and colleagues [64] recently published a proteomic review of the vitreous humor of the eye. Contrasting these findings to the proteome of SLE patients' vitreous humor could shed more light on the pathogenesis of retinopathy in SLE. Dai and colleagues [27] found immunoglobulin J to be upregulated in peripheral blood mononuclear cells. Other mass spectrometry-based techniques could be used, such as multiple reaction monitoring (MRM) and selected reaction monitoring (SRM) LCMS/MS, which allows focused study on only $\mathrm{m} / \mathrm{z}$ ratios of interest, reducing sample processing time and greatly increasing throughput. After the initial biomarker discovery stages, MRM/SRM has been used as a tool in biomarker validation in blood [65] and synovial fluid, specifically in RA patients [66]. Additionally, the speed and potential for multiplexing means MRM/SRM could have clinical utility in patient diagnosis, prognosis, and monitoring [67]. We used a LC-MS/MS approach to identify the M-type phospholipase $\mathrm{A}_{2}$ receptor $\left(\mathrm{PLA}_{2} \mathrm{R}\right)$ as the target antigen in idiopathic membranous nephropathy [68]; antibodies recognizing the $\mathrm{PLA}_{2} \mathrm{R}$ were present in 70 to $80 \%$ of these patients. However, they are not present in any patients with membranous lupus nephritis, which develops in up to $40 \%$ of patients with LN [69]. This suggests that there are unique autoantibodies directed against specific kidney proteins other than the PLA $\mathrm{R}_{2} \mathrm{R}$ in membranous lupus nephritis; therefore, proteomic studies could be designed to identify such target antigens as well as specific epitopes important in this disease.

Even with the strides we have made in the understanding of SLE, it is still a debilitating condition affecting hundreds of thousands of patients every year. While treatments are available, they bring with them significant side effects and frequent failure rates. Recent advances in mass spectrometry technology have allowed an even more thorough analysis of complex samples to better understand the significance of minute changes in the pathogenesis of SLE, while accommodating large sample sizes through multiplexing and high-throughput methods. Furthermore, the options researchers or clinicians have in mass spectrometry techniques are rapidly expanding and have the ability to be tailored to a specific study. It is our hope that this review has afforded the reader a greater knowledge of the potential uses of mass spectrometry and other proteomic technologies in the study of SLE. While a proteomic understanding of disease is by no means a panacea, it offers the potential to help advance our knowledge and understanding of SLE to a point that the disease could be less of a burden for those afflicted.

\begin{abstract}
Abbreviations
AGP, a1-acid-glycoprotein; APM, apoptotic-prone macrophage; CNS, central nervous system; CSF, cerebral spinal fluid; ESI, electrospray ionization; INA, a-internexin; iTRAQ, isobaric tagging for relative and absolute protein quantification; LC, liquid chromatography; LN, lupus nephritis; L-PGDS, lipocalin-type prostaglandin-D synthetase; MALDI, matrix-assisted laser desorption/ionization; MRM, multiple reaction monitoring; MS/MS, tandem mass spectrometry; NPSLE, neuropsychiatric systemic lupus erythematosus; PBMC, peripheral blood mononuclear cell; PLA $R$, phospholipase $A_{2}$ receptor; RA, rheumatoid arthritis; SELDI, surface-enhanced laser desorption/ionization; SLE, systemic lupus erythematosus; SRM, selected reaction monitoring; Tf, transferrin; TOF, time-of-flight.
\end{abstract}

\section{Competing interests}

The authors declare that they have no competing interests.

\section{Acknowledgements}

This work was supported in part by the Juvenile Diabetes Research Foundation award \#1-2011-588

\section{Author details}

'Department of Biochemistry and Molecular Biology, University of Louisville School of Medicine, 570 South Preston St, Baxter Research Building I, Room 204E, Louisville, KY 40202, USA. ${ }^{2}$ Arthritis and Clinical Immunology Program, Oklahoma Medical Research Foundation, 825 NE 13th Street, Oklahoma City, OK 73104, USA. ${ }^{3}$ Department of Medicine, University of Louisville School of Medicine, 570 South Preston St, Baxter Research Building I, Room 204E, Louisville, KY 40202, USA.

Published: 20 February 2012 


\section{References}

1. Cervera R, Khamashta MA, Font J, Sebastiani GD, Gil A, Lavilla P, Aydintug AO, Jedryka-Góral A, de Ramón E, Fernández-Nebro A, Galeazzi M, Haga HJ, Mathieu A, Houssiau F, Ruiz-Irastorza G, Ingelmo M, Hughes GR: Morbidity and mortality in systemic lupus erythematosus during a 5-year period. A multicenter prospective study of 1,000 patients. European Working Party on Systemic Lupus Erythematosus. Medicine (Baltimore) 1999, 78:167-175

2. Molino C, Fabbian F, Longhini C: Clinical approach to lupus nephritis: recent advances. Eur J Intern Med 2009, 20:447-453.

3. Rahman A, Isenberg DA: Systemic lupus erythematosus. N Engl J Med 2008, 358:929-939.

4. Link AJ, Eng J, Schieltz DM, Carmack E, Mize GJ, Morris DR, Garvik BM, Yates JR 3rd: Direct analysis of protein complexes using mass spectrometry. Nat Biotechnol 1999, 17:676-682.

5. Powell DW, Merchant ML, Link AJ: Discovery of regulatory molecular events and biomarkers using 2D capillary chromatography and mass spectrometry. Expert Rev Proteomics 2006, 3:63-74.

6. Powell DW, Rane MJ, Joughin BA, Kalmukova R, Hong J-H, Tidor B, Dean WL, Pierce WM, Klein JB, Yaffe MB, McLeish KR: Proteomic identification of 14-3-3zeta as a mitogen-activated protein kinase-activated protein kinase 2 substrate: role in dimer formation and ligand binding. Mol Cell Biol 2003, 23:5376-5387.

7. Clarke CH, Buckley JA, Fung ET: SELDI-TOF-MS proteomics of breast cancer. Clin Chem Lab Med 2005, 43:1314-1320.

8. Lu X-ye, Chen X-xiang, Huang L-dong, Zhu C-ging, Gu Y-ying, Ye S: Antialpha-internexin autoantibody from neuropsychiatric lupus induce cognitive damage via inhibiting axonal elongation and promote neuron apoptosis. PLOS ONE 2010, 5:e11124.

9. Katsumata Y, Kawaguchi Y, Baba S, Hattori S, Tahara K, Ito K, Iwasaki T, Yamaguchi N, Oyama M, Kozuka-Hata H, Hattori H, Nagata K, Yamanaka H, Hara M: Identification of three new autoantibodies associated with systemic lupus erythematosus using two proteomic approaches. Mol Cell Proteomics 2011, 10:M110.005330.

10. Seko Y, Matsumoto A, Fukuda T, Imai Y, Fujimura T, Taka H, Mineki R, Murayama K, Hirata Y, Nagai R: A case of neonatal lupus erythematosus presenting delayed dilated cardiomyopathy with circulating autoantibody to annexin A6. Int Heart J 2007, 48:407-415.

11. Appenzeller S, Pineau C, Clarke A: Acute lupus myocarditis: Clinical features and outcome. Lupus 2011, 20:981-988.

12. Wijetunga M, Rockson S: Myocarditis in systemic lupus erythematosus. Am J Med 2002, 113:419-423.

13. Comín-Colet J, Sánchez-Corral MA, Alegre-Sancho JJ, Valverde J, LópezGómez D, Sabaté X, Juan-Mas A, Esplugas E: Complete heart block in an adult with systemic lupus erythematosus and recent onset of hydroxychloroquine therapy. Lupus 2001, 10:59-62.

14. Bidani AK, Roberts JL, Schwartz MM, Lewis EJ: Immunopathology of cardiac lesions in fatal systemic lupus erythematosus. Am J Med 1980, 69:849-858.

15. Gazarian M, Feldman BM, Benson LN, Gilday DL, Laxer RM, Silverman ED: Assessment of myocardial perfusion and function in childhood systemic lupus erythematosus. J Pediatr 1998, 132:109-116.

16. Manzi S, Meilahn EN, Rairie JE, Conte CG, Medsger TA Jr, Jansen-McWilliams L, D'Agostino RB, Kuller LH: Age-specific incidence rates of myocardial infarction and angina in women with systemic lupus erythematosus: comparison with the Framingham Study. Am J Epidemiol 1997, 145:408-415.

17. Kurien BT, Newland J, Paczkowski C, Moore KL, Scofield RH: Association of neutropenia in systemic lupus erythematosus (SLE) with anti-Ro and binding of an immunologically cross-reactive neutrophil membrane antigen. Clin Exp Immuno/ 2000, 120:209-217

18. Wang L, Dai Y, Qi S, Sun B, Wen J, Zhang L, Tu Z: Comparative proteome analysis of peripheral blood mononuclear cells in systemic lupus erythematosus with iTRAQ quantitative proteomics. Rheumatol Int 2010 [Epub ahead of print].

19. Ottosson L, Salomonsson S, Hennig J, Sonesson S-E, Dörner T, Raats J, Kuchroo VK, Sunnerhagen M, Wahren-Herlenius M: Structurally derived mutations define congenital heart block-related epitopes within the 200-239 amino acid stretch of the Ro52 protein. Scand J Immuno/ 2005, 61:109-118.

20. Serada S, Fujimoto M, Takahashi T, He P, Hayashi A, Tanaka T, Hagihara K, Yamadori T, Mochizuki M, Norioka N, others: Proteomic analysis of autoantigens associated with systemic lupus erythematosus:
Anti-aldolase A antibody as a potential marker of lupus nephritis Proteomics Clin Appl 2007, 1:185-191.

21. Reed JH, Neufing PJ, Jackson MW, Clancy RM, Macardle PJ, Buyon JP, Gordon TP: Different temporal expression of immunodominant Ro60/60 kDa-SSA and La/SSB apotopes. Clin Exp Immunol 2007, 148:153-160.

22. Briassouli P, Komissarova EV, Clancy RM, Buyon JP: Role of the urokinase plasminogen activator receptor in mediating impaired efferocytosis of anti-SSA/Ro-bound apoptotic cardiocytes: Implications in the pathogenesis of congenital heart block. Circ Res 2010, 107:374-387.

23. Pavon EJ, Munoz P, Lario A, Longobardo V, Carrascal M, AbiÃ jn J, Martin AB, Arias SA, Callejas-Rubio JL, Sola R, Navarro-Pelayo F, Raya-Alvarez E, OrtegoCenteno N, Zubiaur M, Sancho J: Proteomic analysis of plasma from patients with systemic lupus erythematosus: increased presence of haptoglobin alpha2 polypeptide chains over the alpha1 isoforms. Proteomics 2006, 6 Suppl 1:S282-S292.

24. Van Vlierberghe $H$, Langlois M, Delanghe J: Haptoglobin polymorphisms and iron homeostasis in health and in disease. Clin Chim Acta 2004, 345:35-42

25. Chapelle JP, Albert A, Smeets JP, Heusghem C, Kulbertus HE: Effect of the haptoglobin phenotype on the size of a myocardial infarct. N Engl J Med 1982, 307:457-463.

26. Gunteski-Hamblin AM, Song G, Walsh RA, Frenzke M, Boivin GP, Dorn GW 2nd, Kaetzel MA, Horseman ND, Dedman JR: Annexin VI overexpression targeted to heart alters cardiomyocyte function in transgenic mice. Am J Physiol 1996, 270:H1091-1100.

27. Dai Y, Hu C, Huang Y, Huang H, Liu J, LVT: A proteomic study of peripheral blood mononuclear cells in systemic lupus erythematosus. Lupus 2008, 17:799-804.

28. Yi L, Zeng X, Tan H, Ge L, Ji X-X, Lin M, Su Q: Proteomics analysis of apoptosis initiation induced by diallyl disulfide in human leukemia HL-60 cells. Ai Zheng 2009, 28:33-37.

29. Ohsawa S, Watanabe T, Katada T, Nishina H, Miura M: Novel antibody to human BASP1 labels apoptotic cells post-caspase activation. Biochem Biophys Res Commun 2008, 371:639-643.

30. Ortega LM, Schultz DR, Lenz O, Pardo V, Contreras GN: Lupus nephritis: pathologic features, epidemiology and a guide to therapeutic decisions. Lupus 2010, 19:557.

31. Kimura A, Kanoh Y, Sakurai T, Koumura A, Yamada M, Hayashi Y, Tanaka Y, Hozumi I, Takemura M, Seishima M, Inuzuka T: Antibodies in patients with neuropsychiatric systemic lupus erythematosus. Neurology 2010, 74:1372.

32. Kimura A, Sakurai T, Yamada M, Koumura A, Hayashi Y, Tanaka Y, Hozumi I, Takemura M, Seishima M, Inuzuka T: Elevated anti-heat shock protein 60 antibody titer is related to white matter hyperintensities. J Stroke Cerebrovasc Dis 2010 [Epub ahead of print].

33. Reyes-Thomas J, Blanco I, Putterman C: Urinary biomarkers in lupus nephritis. Clin Rev Allerg Immunol 2010, 40:138-150.

34. Oates JC, Varghese S, Bland AM, Taylor TP, Self SE, Stanislaus R, Almeida JS, Arthur JM: Prediction of urinary protein markers in lupus nephritis. Kidney Int 2005, 68:2588-2592

35. Mosley K, Tam FWK, Edwards RJ, Crozier J, Pusey CD, Lightstone L: Urinary proteomic profiles distinguish between active and inactive lupus nephritis. Rheumatology 2006, 45:1497-1504

36. Zhang X, Jin M, Wu H, Nadasdy T, Nadasdy G, Harris N, Green-Church K, Nagaraja H, Birmingham DJ, Yu C-Y, Hebert LA, Rovin BH: Biomarker discovery for lupus nephritis through longitudinal urine proteomics. Kidney Int 2008, 74:799-807.

37. Zhang $X$, Rovin BH: Hepcidin expression by human monocytes in response to adhesion and pro-inflammatory cytokines. Biochim Biophys Acta 2010, 1800:1262-1267

38. Suzuki M, Ross GF, Wiers K, Nelson S, Bennett M, Passo MH, Devarajan P, Brunner HI: Identification of a urinary proteomic signature for lupus nephritis in children. Pediatr Nephrol 2007 .22:2047-2057.

39. Suzuki M, Wiers K, Brooks EB, Greis KD, Haines K, Klein-Gitelman MS, Olson J, Onel K, O'Neil KM, Silverman ED, Tucker L, Ying J, Devarajan P, Brunner HI: Initial validation of a novel protein biomarker panel for active pediatric lupus nephritis. Pediatr Res 2009, 65:530-536.

40. Varghese SA, Powell TB, Budisavljevic MN, Oates JC, Raymond JR, Almeida JS, Arthur JM: Urine biomarkers predict the cause of glomerular disease. J Am Soc Nephrol 2007, 18:913-922.

41. Dong J, Li H, Wang J-B, Yao Y, Yang Q-R: Predictors for neuropsychiatric development in Chinese adolescents with systemic lupus erythematosus. 
Rheumatol Int 2011 [Epub ahead of print].

42. Sibbitt WL Jr, Brandt JR, Johnson CR, Maldonado ME, Patel SR, Ford CC, Bankhurst AD, Brooks WM: The incidence and prevalence of neuropsychiatric syndromes in pediatric onset systemic lupus erythematosus. J Rheumatol 2002, 29:1536-1542.

43. Ndhlovu M, Preuss BE, Dengjel J, Stevanovic S, Weiner SM, Klein R: Identification of a-tubulin as an autoantigen recognized by sera from patients with neuropsychiatric systemic lupus erythematosus. Brain Behav Immun 2011, 25:279-285.

44. Zhang $Y$, Wang J, Xiang $D$, Wang $D$, Xin $X$ : Alterations in the expression of the apurinic/apyrimidinic endonuclease-1/redox factor-1 (APE1/Ref-1) in human ovarian cancer and indentification of the therapeutic potential of APE1/Ref-1 inhibitor. Int J Oncol 2009, 35:1069-1079.

45. Kimura A, Sakurai T, Tanaka Y, Hozumi I, Takahashi K, Takemura M, Saito K, Seishima M, Inuzuka T: Proteomic analysis of autoantibodies in neuropsychiatric systemic lupus erythematosus patient with white matter hyperintensities on brain MRI. Lupus 2008, 17:16-20.

46. Johnson RB, Fearon K, Mason T, Jindal S: Cloning and characterization of the yeast chaperonin HSP60 gene. Gene 1989, 84:295-302.

47. Zhu J, Quyyumi AA, Rott D, Csako G, Wu H, Halcox J, Epstein SE: Antibodies to human heat-shock protein 60 are associated with the presence and severity of coronary artery disease: evidence for an autoimmune component of atherogenesis. Circulation 2001, 103:1071-1075.

48. Kao S-H, Hsu T-C, Yu J-S, Chen J-T, Li S-L, Lai W-X, Tzang B-S: Proteomic analysis for the anti-apoptotic effects of cystamine on apoptosis-prone macrophage. J Cell Biochem 2010, 110:660-670.

49. Dardik R, Inbal A: Complex formation between tissue transglutaminase II (tTG) and vascular endothelial growth factor receptor 2 (VEGFR-2): proposed mechanism for modulation of endothelial cell response to VEGF. Exp Cell Res 2006, 312:2973-2982.

50. Pillai A, Veeranan-Karmegam R, Dhandapani KM, Mahadik SP: Cystamine prevents haloperidol-induced decrease of BDNF/TrkB signaling in mouse frontal cortex. J Neurochem 2008, 107:941-951.

51. D'souza A, Kurien BT, Rodgers R, Shenoi J, Kurono S, Matsumoto H, Hensley K, Nath SK, Scofield RH: Detection of catalase as a major protein target of the lipid peroxidation product 4-HNE and the lack of its genetic association as a risk factor in SLE. BMC Med Genet 2008, 9:62.

52. Ye S, Pang H, Gu YY, Hua J, Chen XG, Bao CD, Wang Y, Zhang W, Qian J, Tsao BP, others: Protein interaction for an interferon-inducible systemic lupus associated gene, IFIT1. Rheumatology 2003, 42:1155.

53. Walters E, Rider V, Abdou NI, Greenwell C, Svojanovsky S, Smith P, Kimler BF: Estradiol targets T cell signaling pathways in human systemic lupus. Clin Immunol 2009, 133:428-436.

54. Pachner AR, Warth JD, Pace A, Goelz S: Effect of neutralizing antibodies on biomarker responses to interferon beta: the INSIGHT study. Neurology 2009, 73:1493-1500.

55. Higgs BW, Liu Z, White B, Zhu W, White WI, Morehouse C, Brohawn P, Kiener PA, Richman L, Fiorentino D, Greenberg SA, Jallal B, Yao Y: Patients with systemic lupus erythematosus, myositis, rheumatoid arthritis and scleroderma share activation of a common type I interferon pathway. Ann Rheum Dis 2011, 70:2029-2036.

56. Pan X, Huang L, Chen J, Dai Y, Chen X: Analysis of synovial fluid in knee joint of osteoarthritis: 5 proteome patterns of joint inflammation based on matrix-assisted laser desorption/ionization time-of-flight mass spectrometry. Int Orthop 2012, 36:57-64.

57. Dieudé M, Senécal J-L, Raymond Y: Induction of endothelial cell apoptosis by heat-shock protein 60 -reactive antibodies from anti-endothelial cel autoantibody-positive systemic lupus erythematosus patients. Arthritis Rheum 2004, 50:3221-3231.

58. Schett $\mathrm{G}, \mathrm{Xu} \mathrm{Q}$, Amberger A, Van der Zee R, Recheis H, Willeit J, Wick G Autoantibodies against heat shock protein 60 mediate endothelial cytotoxicity. J Clin Invest 1995, 96:2569-2577.

59. Qazi KR, Torregrosa Paredes P, Dahlberg B, Grunewald J, Eklund A, Gabrielsson $S$ : Proinflammatory exosomes in bronchoalveolar lavage fluid of patients with sarcoidosis. Thorax 2010, 65:1016-1024.

60. Fietta A, Bardoni A, Salvini R, Passadore I, Morosini M, Cavagna L, Codullo V, Pozzi E, Meloni F, Montecucco C: Analysis of bronchoalveolar lavage fluid proteome from systemic sclerosis patients with or without functional, clinical and radiological signs of lung fibrosis. Arthritis Res Ther 2006, 8:R160

61. Rottoli P, Magi B, Cianti R, Bargagli E, Vagaggini C, Nikiforakis N, Pallini V, Bini L: Carbonylated proteins in bronchoalveolar lavage of patients with sarcoidosis, pulmonary fibrosis associated with systemic sclerosis and idiopathic pulmonary fibrosis. Proteomics 2005, 5:2612-2618.

62. Bargagli E, Penza F, Vagaggini C, Magi B, Perari MG, Rottoli P: Analysis of carbonylated proteins in bronchoalveolar lavage of patients with diffuse lung diseases. Lung 2007, 185:139-144.

63. Bargagli E, Olivieri C, Prasse A, Bianchi N, Magi B, Cianti R, Bini L, Rottoli P: Calgranulin B (S100A9) levels in bronchoalveolar lavage fluid of patients with interstitial lung diseases. Inflammation 2008, 31:351-354.

64. Tamburro D, Facchiano F, Petricoin EF, Liotta LA, Zhou W: Mass spectrometrybased characterization of the vitreous phosphoproteome. Proteomics Clin Appl 2010, 4:839-846

65. Schiess R, Wollscheid B, Aebersold R: Targeted proteomic strategy for clinical biomarker discovery. Mol Oncol 2009, 3:33-44.

66. Liao H, Wu J, Kuhn E, Chin W, Chang B, Jones MD, O'Neil S, Clauser KR, Karl J, Hasler F, Roubenoff R, Zolg W, Guild BC: Use of mass spectrometry to identify protein biomarkers of disease severity in the synovial fluid and serum of patients with rheumatoid arthritis. Arthritis Rheum 2004, 50:3792-3803.

67. Whiteaker JR, Zhao L, Abbatiello SE, Burgess M, Kuhn E, Lin C, Pope ME, Razavi M, Anderson NL, Pearson TW, Carr SA, Paulovich AG: Evaluation of large scale quantitative proteomic assay development using peptide affinity-based mass spectrometry. Mol Cell Proteomics 2011, 10:M110.005645.

68. Beck Jr LH, Bonegio RG., Lambeau G, Beck DM, Powell DW, Cummins TD, Klein $J B$, Salant DJ: M-type phospholipase A2 receptor as target antigen in idiopathic membranous nephropathy. N Eng/ J Med 2009, 361:11-21.

69. Bhinder S, Singh A, Majithia V: Membranous (class V) renal disease in systemic lupus erythematosus may be more common than previously reported: results of a 6-year retrospective analysis. Am J Med Sci 2010, 339:230-232.

70. Li T-wang, Zheng B-rong, Huang Z-xiang, Lin Q, Zhao L-ke, Liao Z-tao, Zhao J-jun, Lin Z-ming, Gu J-ruo: Screening disease-associated proteins from sera of patients with rheumatoid arthritis: a comparative proteomic study. Chin Med J 2010, 123:537-543.

71. Cui Y, Huang M, He Y, Zhang S, Luo Y: Genetic ablation of apolipoprotein A-IV accelerates Alzheimer's disease pathogenesis in a mouse model. Am J Pathol 2011, 178:1298-1308.

doi:10.1186/ar3701

Cite this article as: Korte EA, et al.: Contributions of mass spectrometrybased proteomics to defining cellular mechanisms and diagnostic markers for systemic lupus erythematosus. Arthritis Research \& Therapy 2012, 14:204. 